\title{
Ukrainian Experience of State Regulation of Stock Exchange Activity
}

\author{
$N$. Reznik ${ }^{l}, G$. Abuselidze ${ }^{2, *}, A$. Ostapchuk $^{l}$, and $V$. Tkachuk ${ }^{l}$ \\ ${ }^{*}$ Corresponding author: george.abuselidze@bsu.edu.ge. \\ ${ }^{1}$ National University of Life and Environmental Science of Ukraine, Kiev, Ukraine \\ ${ }^{2}$ Batumi Shota Rustaveli State University, Batumi, Georgia
}

\begin{abstract}
Theme of stock market is on the level of development in some countries. It faces a number of problems for the first time and there are no mechanisms for its overcoming. There are offers how to overcome the most popular problems of countries where the stock market just start to develop. The main part is belonging to state intervention and formation of legislative bases. Due to methods of analysis and generalization the article offers measures and mechanism of action for countries which have the same problems like Ukrainian. This research can be applied as it is or become the basis for development of new recommendations for the regulation of stock market activity.
\end{abstract}

Keywords: stock market, world trade, foreign investments, basic assets, stock exchange activity.

\section{Introduction}

The development of stock markets in the world is one of the most urgent themes of recent years. In some countries, this area is at the level of development, it faces a number of problems for the first time and there are no mechanisms for its overcoming. One of these countries is Ukraine, which is currently in a difficult position and can be a good example for highlighting and demonstration the difficulties that may arise in the processes of development and formation of the stock market. Thus, the article analyzes and uses the state of the stock market of Ukraine to offer a mechanism of effective state regulation of stock market activity [1]. This mechanism for regulating of stock market activity can also be used for other countries that, in their own development, have similar problems at a certain level. This research can be applied as it is or become the basis for developing new recommendations for the regulation of stock market activity. In recent years, bills and stock exchange development programs have been elaborated, but it have not yet found a place in the legislative field, and the economic system in Ukraine today cannot guarantee producers and buyers full protection against inflation and financial losses in the future. Unlike Ukraine, in other countries of the world, there are modern fixed-term markets and markets for forward and futures stock exchange contracts, which provide the maximum protection of all participators of trade. These and other factors of influence hinder the process of developing a «healthy» stock market by slowing down of market economy development.

\section{Methods}

In order to achieve the goal, general scientific and special research methods were used: methods of analysis and synthesis, systematization and generalization, a classification-analytical method for characterizing principles at stock exchange processes, as well as changes in the financial sphere that take place. In the new economy, correlationregression analysis to determine the relationship between of the functioning and development of stock trading in Ukraine and factors affecting its level.

\section{Internal level of state policy}

To format of management principles for stock exchange processes it is expedient to allocate the levels of influence of state regulation on the development of stock trading, depending on which the system of coordination and regulation of wholesale trade processes should be formed, which significantly simplifies the transition from simpler management methods to more highly effective and progressive methodological bases for the introduction of modern management principles. It is expedient to implement the state policy in the field of stock exchange trading on four levels: local, regional, national and international [2]. 
Table 1. Levels of state policy in the field of stock exchange trade.

\begin{tabular}{|c|c|}
\hline $\begin{array}{c}\text { Level of introduction of state } \\
\text { policy in the field of stock } \\
\text { exchange trading }\end{array}$ & Function of level \\
\hline Local & Formation of state policy within stock exchanges \\
\hline Regional & $\begin{array}{c}\text { Regulation of stock exchange relations within the } \\
\text { territorial stock exchange markets }\end{array}$ \\
\hline National & $\begin{array}{c}\text { Improvement of the system of stock exchange relations } \\
\text { within the country }\end{array}$ \\
\hline International & Conducting the state stock exchange policy at the \\
interstate level
\end{tabular}

Source: Authors.

At the local level, it is necessary to improve a number of positions that form a system of stock exchange relations and will be able to synchronize the interaction between the state and the self-regulated organizations of stock exchanges. The organizational structure of the commodity exchange was formed during the evolution of stock exchange institutions and today it is an organizational form, which includes normative and executive components. Based on the foregoing, we can form the key principles for improving the functions performed by the bodies of the internal management of the stock exchange and other organizational units.

On the part of state regulation, it is possible to introduce a system of standardization of stock exchanges, to introduce world trade technologies, to create a favorable investment climate, to improve the legislative and legal framework and to promote the training of specialists. In the process of self-regulation, it is possible to improve the functioning of the arbitration mechanism, to reorganize and optimize the work of the stock exchange bodies, to create a mechanism for accelerating the conclusion of agreements and minimize risks [3]. All these measures on both sides will lead to the process of certification and quality control, to monitoring, to provide clearing and financial guarantees and to strengthen the information function. Unfortunately, despite all advantages of self-regulating stock exchange organizations, it is not necessary to expect positive results at the final stage, because a considerable role is assigned to the state administration in Ukraine, so the most of functions of stock trading cannot be realized without support and intervention of the state bodies. Although should not forget that excessive pressure on the part of the state to internal work of stock exchanges may have also negative influence on the efficiency of its work due to contradictions.

The next level of implementation of the state policy on stock trading is regional. At this level, as in others, there is a set of mistakes on the part of the state bodies and the lack of a clear mechanism of policy shaping for developing stock exchange relations. Significant is the participation of local bodies and local governments in stock exchange activities at the regional level. Of course, such participation involves consistency of action both at the state level and directly at the level of the governing bodies of stock exchanges.

Increasingly, there is a problem of participation of small business entities in stock trading, since the stock market involves the wholesale purchase and sale of small quantities of goods or raw materials, which effectively prevents the entry of small commodity producers into the legalized wholesale market. At the same time, functioning of small and medium-sized businesses is a priority direction of the economy of many leading countries of the world. The rapid development of a small business will positively influence the activation of the market economy, give it flexibility, stimulate the resources of the population, and mobilize the anti-monopoly potential. Since the stock exchange trade is a legalized form of wholesale trade, there is a need to attract small and medium-sized businesses to trading processes on the stock exchanges by enabling business entities to sell or buy at stock exchanges [4]. The specifics of the commodity exchanges' activities are the sale and purchase of a large number of goods, which is why a certain problem for small businesses to distribute relatively small quantities of products through the stock trading network. Most small businesses do not get guarantees on the product market, and the risks that arise at all stages of its activity often lead to negative consequences.

The first step should be reforming the legislative framework for expanding the opportunities and rights for small businesses, as well as reforming the general legal and regulatory framework for the functioning of stock trading in Ukraine. The next steps will be creation of voluntary associations of small business entities to satisfy the common needs of product sales on stock exchanges. Since small enterprises that produce certain type of goods or services can be located in different regions, creation of so-called unions (clusters) or groups of small commodity producers is possible through a single network by creating a web-portal, which will contain the necessary information [5].

It is important to form unified system of standardization and certification of products, which becomes the object of trade at stock exchanges. Product certification has to be state-owned and sustainable, as close as possible to world standards. To increase the interest of small commodity producers is possible with creating conditions for granting certain advantages for agricultural producers. An interest of entity, which receives opportunity to grow one or another crop, is to make organic or ecologic farming, if authorized government agencies monitoring it. When the final product is released to the stock market, the commodity producer has an appropriate certificate, which is evident that the product meets a certain standard [6]. Eventually, such process provides a number of benefits to all parties involved in stock trade.

The national level implies conducting of state policy in a broader sense within the country. It cannot be said that now there is no general government policy in the field of stock exchange, but it is conducted at a rather low level and needs deep reforms. Global trends in economic, industrial and social development form a clear idea of how to act on the state level. At the same time, it is impossible to say certainty that global stock exchange experience of trade can be 
completely designed in Ukraine, because the existing economic system here is at a so low level that needs a radical adjustment. To stabilize the processes of the stock exchange development, it is necessary to form a clear mechanism of action on the part of the state. Today, the state pays lack of attention to the scientific component of stock exchange activity. Scientists in the field of economics and stock exchange practitioners have lack of financial and investment foundation to analyze and develop forecasts. Data that used to conduct research is difficult to find. In line with this, there is a problem of developing innovations in the field of research. State policy in the field of innovation is a separate important component of the whole system of state regulation. The priority directions of its development in Ukraine should be: support of basic scientific research in the field of economics and stock activities; development and support of industries and increase of enterprise' competitiveness; financial support; improvement of the support system for commodity producers; involving potential investors [7].

\section{External level of state policy}

The next level of state policy is international. In the field of stock trading, this concerns, first of all, the entry into the international wholesale market of domestic commodities and the attraction of foreign investment. To form effective methodological principles, it is necessary to put the following goals before the government and the state bodies: develop a methodology and system of state regulation of stock trading, taking into account the peculiarities of economic and social development of the country; to determine the main economic, social and scientific directions of the development of stock exchange relations in the future, both in general for the country and for certain regions; to identify and specify ways to achieve goals; to form the organizational and legal basis for processes of transition to modern market relations; to monitor the implementation of the objectives, programs and other elements by the relevant authorities and institutions [8]. The only scheme of action at the four levels of management of stock exchanges is shown in Table 2.

Table 2. System of measures of state regulation of stock exchange trade in Ukraine.

\begin{tabular}{|c|l|}
\hline Level & \multicolumn{1}{c|}{ Measures of influence } \\
\hline Local & $\begin{array}{l}\text { - } \text { reorganization of the structure of stock exchanges } \\
\text { - minimization of risks in conclusion of transactions } \\
\text { - increasing the level of marketing services } \\
\text { - formation of a modern informational environment }\end{array}$ \\
\hline - introduction of regional programs for the support and development of small \\
enterprises \\
- increase participation of local and district state institutions in the \\
Regional & $\begin{array}{l}\text { - creation of training programs at the state expense } \\
\text { - creation of web-portals and Internet-services for the association of small } \\
\text { business entities } \\
\text { - providing for the possibility of concluding stock exchange agreements on } \\
\text { the terms of SPOT, forward and futures } \\
\text { - certification of elevators and warehouses }\end{array}$ \\
\hline - support of basic scientific research in the field of economics and stock \\
activities \\
- development and support of industries and increase of enterprise' \\
competitiveness \\
- financial support \\
- improvement of the support system for commodity producers \\
- involving potential investors
\end{tabular}

Source: Authors.

The transparency of the stock market will became the result of the formation of methodological principles for the functioning of the state stock exchange trading policy, as well as the acceleration of international capital turnover and the creation of conditions for macroeconomic planning at the national and international levels. Activating the development of the informational space and increasing the use of Internet resources will ensure the involvement of interested stock market participants; expand the marketing opportunities of stock exchanges [9]. The formation of an 
effective legal framework will enable stock exchange participants to obtain guarantees for the execution of stock exchange transactions and the ability to insure price risks. The stock market will in fact become a place for free pricing in these conditions, which will promote highly effective economic relations. Since the main place of concentration of goods and services is the stock exchange, it is necessary to pay attention to the problems of functioning of stock exchanges dependence of its quantity on the efficiency of activity. The number of registered and operating stock exchanges in Ukraine is quite large. It is necessary to reorganize commodity stock exchanges, leaving or combining small and medium-sized stock exchanges into more powerful units, and to increase the number of brokerage offices. For example, leave regional commodity stock exchanges or those stock exchanges whose activities are justified by results. From the side of state bodies and a special newly created body in the field of regulation of stock exchange activities, which will conduct the procedure of licensing stock activities, it is necessary to consider the rationality of the territorial location of stock exchanges. It is also possible to achieve optimization in the process of reducing the number of stock exchanges by monitoring its activities and controlling the reporting time about activities of stock exchange institutions. This implies the establishment by a law of a certain period during which the registered stock exchange unit has to submit a report of the established form regarding the results of its activities.

Today in the system of economic relations of the world considerable attention is paid to marketing activity, which covers the formation of demand for stock services and satisfaction of stock exchange interests of clients. One of the key goals of stock marketing is constant involvement of new clients. Significant role is taken by the risks as among the factors influencing on functioning of the stock market. Another task of stock marketing is to identify the sources of risks and minimize its. It is worth considering that the right choice of marketing strategies depends on a number of factors, such as the position of product groups on the stock market, the level of marketing costs, a set of marketing measures. Marketing events on the stock exchanges include such stages as studying potential customers, studying the client's motives who entering into a contract, analyzing the stock market, studying the types of stock services and possible operations, studying the components of the promotion of stock commodities to the end point, that is, the client, research of the competitive environment and potential competitors and implementation of promotional measures. The significant role of self-regulatory bodies in stock exchange activities should be re-emphasized. These bodies are actively involved in the functioning of the stock market and trade.

According to the legislation of Ukraine, self-regulatory bodies are defined as commercial non-profit organizations which are not part of system of state bodies' management. Generally, self-regulatory organizations were created as regulators of financial services markets, and subsequently it began to extend its functions and today play an important role in many processes that are related to stock exchange activities.

It is appropriate to attribute to the powers and functions of self-regulatory organizations: development of rules and standards for stock exchange activities; protection of the participants rights of stock exchange relations; monitoring and forecasting of the stock market; introduction of proposals for the improvement of the legislation in the field of stock exchange activities; organization of professional training; formation and maintenance of information base; delegation of representatives of self-regulatory organizations to state bodies. However, the organizational and other aspects of selfregulatory organizations are not sufficiently researched and require attention from the legal, personnel and regulatory framework. Formation of common mechanism for regulating stock exchange activities needs for closer interaction between self-regulatory organizations and the newly established regulatory body. This is possible with division of powers between all bodies that are related to the system of stock exchange activities [10]. The main goal of the selfregulatory bodies' activity is to increase the efficiency of the commodity stock market through the economic, technical and organizational measures, the implementation of which should take place with the participation of a common supervisory body with self-regulatory organizations.

For the effective functioning of stock exchanges and stock exchange relations, it is offered:

- to create a department for the development of stock exchange activities, which will be able to regulate issues that are involved with the state bodies;

- to develop a structure, provisions, concept and a state program that will fully outline the field of influence and activity of the department for the development of stock exchange activities [11].

\section{Conclusions}

The mechanism of the functioning and development of stock trading in Ukraine can be created through the establishment of clear standards of activity, taking into account modern requirements. Implementation of the state policy in the area of stock exchange activity at the local level will ensure its development within the stock exchange units, at the regional level - the regulation of stock exchange relations within the territorial stock exchange markets, at the national level - the improvement of stock exchange relations at the state level, at the international level - the conduct of the external state stock exchange policy. There is a need to attract small and medium-sized businesses to trading processes on stock exchanges by enabling business entities to sell or buy products or services at stock exchanges, where an important component is the formation of a unified system of standardization and certification of products that becomes the object of trading on stock exchanges.

Strengthening the function of marketing activities in the system of stock exchange relations involves the formation of demand for stock services and customer satisfaction. One of the key goals of stock exchange marketing is the 
continuous attraction of new clients, which should take place taking into account the factors affecting the functioning of the stock market, where risk plays a significant role, and the task of stock marketing is to identify the sources of risk and minimize it. The implementation of effective marketing activities includes the study of potential customers, customer motivation, stock market analysis, stock market research, the study of the components of the stock products promotion, the study of the competitive environment, the implementation of promotional activities. Reorganization of commodity stock exchanges should take place by uniting small and medium-sized stock exchanges into more powerful, increasing number of brokerage offices.

The transparency of the stock market will be result of the introduction of a mechanism for the direct participation of the state into the stock exchange activities. The acceleration of international capital turnover and the creation of conditions for macroeconomic planning at the national and global levels will be too. Activating the development of the information space and increasing the use of Internet-resources will ensure attraction of new participants into stock trading, expand the marketing opportunities of stock exchanges, and the formation of an effective legal framework will enable stock exchange participants to obtain guarantees for the implementation of stock exchange transactions and minimize risks.

\section{References}

1. A. Agapova, Conventional mutual index funds versus exchange-traded funds. Journal of Financial Markets 14(2), 232-343 (2011).

2. T.G. Andersen, D. Dobrev, E. Schaumburg, Integrated quarticity estimation: Theory and practical implementation. Nonlinear and Financial Econometrics Conference: A Tribute to A. Ronald Gallant (Toulouse, France, May 19-21, 2011) (2011).

URL: http://idei.fr/sites/default/files/medias/doc/conf/finet/annee_2011/quarticity_rev_1105_v8\%5b2\%5d.pdf. Accessed: 15.07.2019.

3. V. Cheung, R. Ingram, K. Patel, Next generation risk management. Market Voice Magazine, 25 th September 2018. (2018). URL: https://marketvoice.fia.org/articles/next-generation-risk-management. Accessed: 15.07.2019.

4. L.K. Grant, Trading risk: Enhanced profitability through risk control (John Wiley \& Sons Hoboken, USA, New Jersey, 2004).

5. J.J. Murphy, Technical analysis of the financial markets: A comprehensive guide to trading methods and applications (Prentice Hall Press, New Jersey, 1999).

6. S. Mikhailov, U. Noegel, Heston's stochastic volatility model implementation, calibration and some extensions. Wilmott Magazine, 1, 74-79 (2005).

7. P.D. Leedy, J.E. Omrod, Practical research: Planning and design (8th ed.) (Prentice Hall Press, New Jersey, 2005).

8. N.P. Reznik, Entrepreneurial firm: Organizational aspect (Kyiv International University, Ukraine, Kyiv, 2016).

9. N.P. Reznik, International practice of investing in the agrarian sector. Culture of the People of the Black Sea, 147, 77-80 (2008).

10. W.F. Sharpe, G.J. Alexander, J.W. Bailey, Investments (6th ed.) (Prentice Hall Press, New Jersey, 1998).

11. W.F. Sharpe, Investors and markets: Portfolio choices, asset prices and investment advice (Princeton University Press, Princeton, NJ, 2006). 